\title{
Isolation, Characterization and Mapping of Mandelate Pathway Mutants of Acinetobacter calcoaceticus
}

\author{
By DINA VAKERIA, ${ }^{+}$ALAN VIVIAN ${ }^{1 *}+$ AND CHARLES A. FEWSON 2 \\ 'School of Biological Sciences and Environmental Health, Thames Polytechnic, Wellington Street, \\ London SEI8 6PF, UK \\ ${ }^{2}$ Department of Biochemistry, University of Glasgow, Glasgow GI2 8QQ,UK
}

(Received 4 April 1984)

\begin{abstract}
Mutants of Acinetobacter calcoaceticus EBF 65/65 that could not grow on intermediates of the mandelate or benzyl alcohol pathways were isolated and in some cases the enzymic lesions were identified. Several catabolic markers were mapped using the plasmid pAV1. The mandelate genes appeared to be clustered near the auxotrophic marker phe-l but were not all contiguous with each other. The gene responsible for the appearance of the novel $L(+)$-mandelate dehydrogenase appeared to be close to a gene responsible for the activity of the original $\mathrm{D}(-)$ mandelate dehydrogenase.
\end{abstract}

\section{INTRODUCTION}

A number of bacteria and fungi can metabolize mandelate but the precise nature of the enzymes and of the regulation of their expression varies from organism to organism (Bhat \& Vaidyanathan, 1976; Kenyon \& Hegeman, 1979). Acinetobacter calcoaceticus wild-type strain EBF $65 / 65$ can grow on $D(-)$-mandelate and some mutants with a novel $I(+)$-mandelate dehydrogenase can also grow on $\mathrm{L}(+)$-mandelate (Hills \& Fewson, 1983a, $b$ ). In addition, $A$. calcoaceticus metabolizes benzyl alcohol by a pathway which converges with that for the oxidation of mandelate (Fig. 1).

A start has been made on mapping some of the genes involved in mandelate metabolism by pseudomonads. In Pseudomonas putida the genes encoding the first five enzymes of the mandelate pathway seem to be linked and may even be contiguous (Chakrabarty et al:, 1968; Chakrabarty \& Gunsalus, 1969; Wheelis \& Stanier, 1970; Wheelis, 1975; Hegeman \& Root, 1976). These genes show supra-operonic clustering with genes of functionally related pathways (Wheelis \& Stanier, 1970; Leidigh \& Wheelis, 1973). The situation in P. aeruginosa is rather different. Whilst there is some clustering of genes for related pathways, two of the mandelate genes are separated by a group of genes encoding enzymes for the degradation of benzoate and catechol (Kemp \& Hegeman, 1968; Rosenberg \& Hegeman, 1969).

The aims of the present work were threefold. First, to obtain mutants of $A$. calcoaceticus that would be useful in physiological and biochemical studies. Secondly, to obtain some information about the genetic organization of the mandelate pathway to allow comparison with the situation in pseudomonads. Thirdly, to see whether the gene responsible for the appearance of the novel $L(+)$-mandelate dehydrogenase activity mapped close to that of the original $D(-)$-mandelate dehydrogenase; these two enzymes have very similar properties and are co-ordinately regulated (Hills \& Fewson, 1983a, b). Some mutants of $A$. calcoaceticus wild-type strain NCIB 8250 have been obtained (Livingstone \& Fewson, 1972; Fewson et al., 1978; Hills \& Fewson, 1983a, b), but unfortunately there is no genetic mapping system available for this strain. We therefore

† Present address: Department of Biological Sciences, University of Dundee, Dundee DD1 4HN, UK. $\$$ Present address: Department of Science, Bristol Polytechnic, Coldharbour Lane, Frenchay, Bristol BSI6 IQY, UK. 


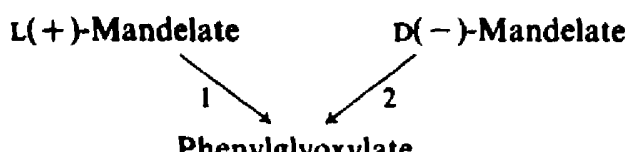

Phenylglyoxylate

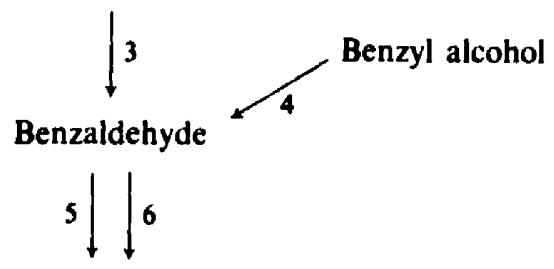

Benzoate

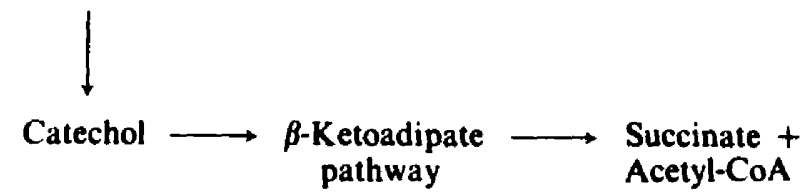

Fig. I. Metabolism of mandelate and benzyl alcohol by A. calcoaceticus EBF 65/65. The wild-type strain grows on only the $\mathrm{D}(-)$-isomer of mandelate but some mutants have a novel $\mathrm{L}(+)$-mandelate dehydrogenase (1) and can grow on the $L(+$-isomer (Hills \& Fewson, 1983b). D-Mandelate dehydrogenase (2), L ( +)-mandelate dehydrogenase (when present), phenylglyoxylate decarboxylase (3) and benzaldehyde dehydrogenase 1 (5) are co-ordinately induced by phenylglyoxylate and are designated the regulon-I enzymes. Benzyl alcohol dehydrogenase (4) and benzaldehyde dehydrogenase II (6) are co-ordinately induced by benzaldehyde or benzyl alcohol and are designated the regulon-2 enzymes. Further details were given by Hills \& Fewson (1983b).

embarked on experiments with the wild-type strain EBF $65 / 65$ because it has a mandelate pathway which is very similar to that in strain NCIB 8250 (Hills \& Fewson, 1983b) and about 23 of its chromosomal genes have been mapped using the plasmid RP4 (Towner \& Vivian, 1976a; Towner, 1978). Plasmid pAV1, which specifies resistance to sulphonamides, was later shown to mobilize the chromosome at a higher frequency (Hinchliffe \& Vivian, 1980b) and this has been used for mapping in the present work.

\section{METHODS}

Growth of bacteria. Strains of A. calcoaceticus are listed in Table 1. Escherichia coli C600 (pRP14+) (RP4 : : Tn7: $A^{R} \mathrm{Km}^{R} \mathrm{Tc}^{R} \mathrm{Tp}^{R} \mathrm{Sm}^{R}$; Barth \& Grinter, 1977) was obtained from Dr P. T. Barth, ICI Corporate Laboratory. Runcorn, Cheshire, UK.

Minimal medium, tryptone soya agar and nutrient broth were as described by Towner \& Vivian (1976a) and salts medium as described by Hills \& Fewson (1983 b).

A. calcoaceticus was grown at $23^{\circ} \mathrm{C}$ for the measurement of enzyme activities and at $28^{\circ} \mathrm{C}$ in all other experiments; $E$. coli was grown at $37^{\circ} \mathrm{C}$.

Sulphadiazine (Sigma) and trimethoprim lactate (Burroughs Wellcome) were used at $500 \mu \mathrm{g} \mathrm{ml} \mathrm{l}^{-1}$ and tetracycline. $\mathrm{HCl}$ (Sigma) at $5 \mu_{\mathrm{g}} \mathrm{ml}^{-1}$.

Mutagenesis. EMS (Sigma) was added to an overnight nutrient broth culture to give a final concentration of $2 \%$ $(w / v)$ and subsequently the culture was incubated on a rotary shaker for $2 \mathrm{~h}$. The bacteria were centrifuged and the pellet washed in quarter-strength Oxoid Ringer's solution to remove any traces of EMS and resuspended in $5 \mathrm{ml}$ nutrient broth; the suspension was then incubated on a rotary shaker for $4 \mathrm{~h}$. A suitable dilution of the culture was then spread on tryptone soya agar to give about 100 colonies per plate. After 48 h incubation, the bacteria were replica plated on selective media. Potential catabolic mutants were plated on salts medium solidified with $1.5 \%$ (w/v) Difco Bacto Agar and containing appropriate auxotrophic supplements and carbon sources, in the following order : benzyl alcohol ( $5 \mathrm{mM}), \mathrm{D}(-)$ or $\mathrm{L}(+)$-mandelate ( $5 \mathrm{mM}$ ), phenylglyoxylate ( $5 \mathrm{mu})$, benzoate ( $2 \mathrm{mM}$ ). Plates were examined after incubation for $48 \mathrm{~h}$.

Filter matings and analysis of recombinants. Conjugative plasmid pA VI (Hinchliffe \& Vivian, 1980a) was used in the method described by Towner \& Vivian $(1976 \mathrm{a}$ ). Recombinants were analysed for co-inheritance as described by Towner (1978). 
Table 1. Strains of A. calcoaceticus

All strains were derived from wild-type EBF $65 / 65$ ( $\mathrm{Mdd}^{\circ} \mathrm{Mdl}^{\mathrm{n} 0} \mathrm{Pgc}^{0} \mathrm{Bad}{ }^{0}$ ) and unless stated otherwise harboured pAV2 (Hinchliffe et al., 1980).

Strain

EBF 65/65
C48
C426
C484
C4103
C4151
C4161
C4183
C4185

C4201

C4205

C4207

$\mathrm{C} 4223$

C4226

$\mathrm{C} 4248$

C4267

C4279

C4289

C4290

C4295

C4408

C4413

C4420

C4435

C4437

C4438

C4439

C4440

C444I

C4664

\section{Characteristics*}

\author{
Wild-type \\ ile-I met-I \\ his-I Irp-2 \\ pht-l thi-2 \\ leu-2 phe-I thi-2 \\ his-1 trp-2 pAVI + \\ phe-I thi-2 pAV2 \\ cys-3 phe-1 mdd-1 pgc-1 \\ ala-I cys-3 pAVI*
}

ile-l met-l Badng

ile-l met-I Badno

ile-I met-I Bad ${ }^{\text {no }}$

phe-I thi-2 mdd-I pgc-l pAV2

ile-I mes-1 mdd-2

ile-l met-l mall-l

ala-l met-l mdd-2 pAVI *

cys-3 trp-2 pAVI +

mel-l phe-l mdd-2

met-l phe-I mdd-I pgc-I

met-l phe-1 mad-2 mdl-2

ala-l his-I leu-2 mdl-2 pAVI +

mdd-3

ile-l met-l $\mathrm{Bad}^{{ }^{{ }^{\circ}}} \mathrm{Mdd}^{\mathrm{n}_{0}} \mathrm{Asa}^{3} \mathrm{Hg}^{\mathrm{s}}$

met-1 trp-2 mad-3 pAVI +

his-I met-1 trp-2 mdd-3 pAVI *

ala-I his-1 trp-2 mdd-3 pAVI *

ile-I met-I mdl-I pAVI +

phe-1 thi-2 pAV1 *

ile-l met-l mdc-l pAVI *

ile-I met-1 mac-l
Reference or source

Towner \& Vivian (1976a)

Towner \& Vivian (1976b)

Hinchliffe \& Vivian (1980b)

Hinchliffe et al. (1980)

EMS treatment of $\mathbf{C 4 8 4}$

Hinchliffe \& Vivian (1980b)

Hinchliffe et al. (1980)

Cross DV45, this paper

Cross DV6 (Vakeria, 1982): C4151 × C459

(ala-l cys-3)

EMS treatment of $\mathbf{C 4 8}$

EMS treatment of $\mathrm{C48}$

EMS ireatment of $\mathrm{C} 48$

Spontaneous mutant of C416I

EMS treatment of $\mathrm{C} 48$

Hills \& Fewson (1983b)

Cross DV32 (Vakeria, 1982): C4185 × C4226

Cross DV28 (Vakeria, 1982): C4185 × C4275

(met-I trp-2)

Cross DV38, this paper

Cross DV39 (Vakeria, 1982): C4266

(his-l phe-l mdd-I pgc-l pAVI +) $\times$ C4275

Spontaneous mutant of C4289

Cross DV52 (Vakeria, 1982): C4287

(ala-1 his-1 leu-2 trp-2 pAVI $\left.{ }^{+}\right) \times C 4295$

EBF 65/65; this paper

C4205 (Vakeria, 1982)

\}

Cross DV219a (D. Vakeria, unpublished):

C4426 (ala-l his-I met-1 irp-2 rif $^{\mathrm{k}}$ pAVI $\left.{ }^{+}\right) \times \mathrm{C} 4413$

Cross DV221 (D. Vakeria, unpublished):

C4434 (phe-1 thi-2 pAV2- pAV1 ${ }^{+}$) $\times$C4248

Cross DV224, this paper

Cross DV223 (D. Vakeria, unpublished):

$\mathrm{C} 4434 \times \mathrm{C} 4664$

Hills \& Fewson (1983b)

- Genotype designations are standard (Demerec et al., 1966; Novick et al., 1976) except for: mdc, constitutive for the regulon-1 enzymes: $m d d$, no growth on $\mathrm{D}(-)$-mandelate: $m d l$, growth on $\mathrm{L}(+)$-mandelate; $p g c$, no growth on phenylglyoxylate. For phenotypes the superscripts ' $g$ ' and 'ng' indicate 'growth' or 'no growth' respectively on: Mdd, D(-)-mandelate; Mdl, L(+)-mandelate: Pgc, phenylglyoxylate; Bad, benzyl alcohol.

Use of iransposon $T n 7$. Filter mating between A. calcoacericus EBF $65 / 65$ and $E$. coli $C 600$ was done as outlined above. The bacteria were plated on minimal medium containing tetracycline and trimethoprim. A single colony was inoculated into nutrient broth containing trimethoprim and incubated at $4^{\circ} \mathrm{C}$ for $14 \mathrm{~d}$. The bacteria grew at this temperature and the resulting culture was then diluted and spread on tryptone soya agar; after $48 \mathrm{~h}$ incubation at $28{ }^{\circ} \mathrm{C}$ the resulting colonies were replica plated to test for resistance to tetracycline and trimethoprim and for the - ability to grow on $\mathrm{D}(-)$-mandelate, phenylglyoxylate, benzyl alcohol or benzoate.

Measurement of enzyme activities. Bacteria were grown and harvested as described by Hills \& Fewson (1983 b) except that the inoculum was $12.5 \%(\mathrm{v} / \mathrm{v})$ and the cultures $(80 \mathrm{ml}$ in $250 \mathrm{ml}$ conical fiasks) were incubated on a rotary shaker before centrifugation. Activities of $\mathrm{L}(+)$ and $\mathrm{D}(-)$-mandelate dehydrogenases, phenylglyoxylate (benzoylformate) decarboxylase (EC 4.1.1.7) and benzyl alcohol dehydrogenase were measured as summarized by Hills \& Fewson ( $1983 b$ ). Activities of the two benzaldehyde dehydrogenases were estimated separately on the basis of their different heat stabilities (Livingstone et al., 1972). Extracts prepared by ultrasonic treatment (Hills \& Fewson, $1983 b$ ) were diluted with an equal volume of $0.1 \mathrm{M}$-sodium pyrophosphate buffer, pH 9.5. and assayed immediately using the procedure of Beggs \&ewson (1977) (benzaldehyde dehydrogenase I + II) and then after $4 \mathrm{~h}$ incubation at $37^{\circ} \mathrm{C}$ (benzaldehyde dehydrogenase I); the activity of benzaldehyde dehydrogenase II was 
estimated as the difference between the two rates. This procedure is more convenient than that used previously (Livingstone et al., 1972) and its reliability was confirmed by measuring the enzyme activities of mixtures of extracts of bacteria that had been grown in the presence of mandelate, thiophenoxyacetate or benzyl alcohol. Catechol 2,3-oxygenase (EC 1.13.11.2) activity was measured by the spectrophotometric procedure of SalaTrepat \& Evans (1971) and catechol 1,2-oxygenase (EC 1 13.11 .1) by the method of Hegeman (1966). All mutants were grown and assayed at least twice; representative results are given in the text.

\section{RESULTS AND DISCUSSION}

\section{Isolation of mutants and their characterization}

Mutants which contained a novel $L(+)$-mandelate dehydrogenase or which were constitutive for the mandelate enzymes could be isolated without difficulty from a range of parental strains using established positive selection techniques (Hills \& Fewson, 1983a,b) but blocked mutants were more difficult to obtain. More than $10^{5}$ colonies of wild-type strain EBF 65/65 and auxotrophic strains $\mathrm{C48}, \mathrm{C} 426$ and $\mathrm{C4161}$ were screened in attempts to isolate mutants lacking one or more enzymes of the mandelate or benzyl alcohol pathways. Several enrichment and selection techniques were used, including some that were moderately successful with wild-type strain NCIB 8250 (e.g. Livingstone et al., 1972; Ahlquist et al., 1975). Mutagenesis with EMS was used in some experiments. Only 43 mutants were obtained which could not grow on one or more intermediates of the pathways. Some of these mutants proved to be unstable but others (Tables I to 4) were suitable for mapping work.

No stable mutants were obtained in which the activity of benzyl alcohol dehydrogenase and/or benzaldehyde dehydrogenase II was diminished; this was particularly unfortunate because it may be necessary to delete benzaldehyde dehydrogenase II activity before attempting to isolate mutants lacking benzaldehyde dehydrogenase I. Surprisingly, some mutants (e.g. C4201) which could not grow on benzyl alcohol contained elevated activities of the regulon-2 enzymes (Tables 2 and 3). Crosses using mutants of this sort sometimes gave rise to unexpected phenotypes in the progeny. Thus, in a cross involving $C 4151$ and $C 4201$, both parents could grow on $D(-)$-mandelate but when 201 recombinants from the four auxotrophic selections were tested, one was found to be unable to grow on either phenylglyoxylate or $D(-)$-mandelate. Further unexpected recombinants, including some that were $\mathrm{Mdd}^{\mathrm{no}} \mathrm{Pgc}^{\mathrm{ng}}$ and others that were

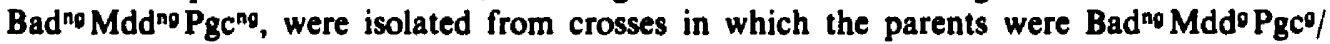

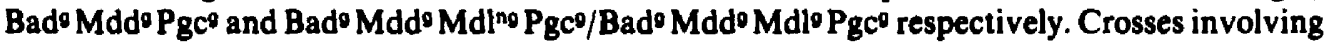
strains which were unaltered in their catabolic activities with respect to the wild-type strain failed to yield unexpected phenotypes, indicating that segregants unable to grow on certain aromatic substrates arose only in crosses involving strains already altered in their catabolic abilities. These observations indicate that there may be some sort of genetic interaction between regulons 1 and 2 .

Mutant C4413 (mdd-3). An RP4 derivative carrying transposon Tn7, pRP14 (RP4:: Tn7; Barth \& Grinter, 1977), was used in an attempt to isolate catabolic mutants. Strain EBF 65/65 can grow at $4{ }^{\circ} \mathrm{C}$, but replication of RP4 appears to be hindered at this temperature (Errington, 1981). The introduction of pRP14 into strain EBF $65 / 65$ followed by growth at $4{ }^{\circ} \mathrm{C}$ and selection for trimethoprim resistance could result in the transposition of $\mathrm{Tn} 7$ into the bacterial chromosome or into another plasmid. Only one variant strain was isolated by this procedure; this was C4413, which failed to grow on D(-)-mandelate but showed wild-type behaviour towards the other substrates tested (Table 2) and lacked $D(-)$-mandelate dehydrogenase activity (Table 3). The pattern of enzyme activity is consistent with phenylglyoxylate, but not mandelate, being the inducer of the regulon-l enzymes; this specificity is the same as that found in wild-type strain NCIB8250 (Livingstone \& Fewson, 1972). At first, the strain was resistant to both trimethoprim (indicative of Tn7) and tetracycline (indicative of RP4), and the presence of pRPI4 was confirmed by agarose gel electrophoresis. Wild-type strain EBF $65 / 65$ has been shown to harbour a plasmid pAV2 which mediates a restriction and modification system influencing the inheritance of pAVI (Hinchliffe et al., 1980). In mutant C4413, the band corresponding to pAV2 had increased in size by approximately 1 to $2 \mathrm{MDal}$. With repeated 
Table 2. Growth of strains of A. calcoaceticus on various intermediates of the mandelate and benzyl alcohol pathways

Growth was tested on salts medium solidified with $1.5 \%$ (w/v) Difco Bacto Agar containing appropriate auxotrophic supplements. The substrates were tested at $5 \mathrm{mM}$, except for benzoate which was used at $2 \mathrm{~mm}$. + , Growth; - , no growth.

\begin{tabular}{|c|c|c|c|c|c|c|}
\hline \multirow[b]{2}{*}{ Strain } & \multirow[b]{2}{*}{$\begin{array}{l}\text { Carbon } \\
\text { source }\end{array}$} & \multicolumn{5}{|c|}{ Growth } \\
\hline & & $\mathbf{L}(+)$-Mandelate & $D(-)$-Mandelate & Phenylglyoxylate & $\begin{array}{l}\text { Benzyl } \\
\text { alcohol }\end{array}$ & Benzoate \\
\hline Vild-type EB & & - & + & + & + & + \\
\hline 4201 & & - & + & + & - & + \\
\hline 4223 & & - & - & - & + & + \\
\hline 4226 & & - & - & + & + & + \\
\hline 4295 & & + & - & + & + & + \\
\hline 4413 & & - & - & + & + & + \\
\hline
\end{tabular}

subculturing, mutant C4413 gradually lost pRP14 and became sensitive to both trimethoprim and tetracycline; however, the $\mathrm{Mdd}^{\text {ng }}$ phenotype and the apparent insertion in pAV2 were retained.

We have not been able to determine whether mutant $\mathrm{C} 4413$ arose as a direct effect of transposition, as a result of some indirect effect of $\mathrm{Tn} 7$ or by some other mechanism.

Mutant C4223 (mdd-1 pgc-l). This mutant was isolated as a spontaneous variant of strain $C 4161$ and was unable to grow on $D(-)$-mandelate or phenylglyoxylate (Table 2). Activities of $D(-)$-mandelate dehydrogenase, phenylglyoxylate decarboxylase and benzaldehyde dehydrogenase I were all absent (Table 3 ) and so this may be a regulatory mutant. Unlike the situation in the parental strain C4161 or the wild-type EBF $65 / 65$, benzyl alcohol dehydrogenase and benzaldehyde dehydrogenase II (the regulon-2 enzymes) were induced in the presence of phenylglyoxylate, the inducer of the regulon-1 enzymes (Table 3). Similar behaviour was observed for certain mandelate pathway mutants of $A$. calcoaceticus wild-type strain NCIB 8250 (Livingstone \& Fewson, 1972). There is no clear explanation of this interaction between the two regulons; however, it is reminiscent of the observation that the regulon-2 enzymes cannot be induced in mutants constitutive for the mandelate enzymes (Beggs \& Fewson, 1977; Fewson et al., 1978; Hills \& Fewson, 1983b). It appears that there may be some sort of reciprocal expression of the two systems and this in turn may be connected with the unexpected isolation of Mdd ${ }^{\text {ng }}$ recombinants from crosses involving Bad $^{\text {no }}$ Mdd' $^{\circ}$ parents described above.

The spontaneous occurrence of mutant $\mathrm{C} 4223$ was unexpected because no spontaneous $\mathrm{Mdd}^{\text {ng }}$ variants were obtained with wild-type strain EBF $65 / 65$ or auxotrophic mutants C48, C426 or C484. However, all these strains contained pAV2 whereas mutant C4161 lacked this plasmid. Subsequent preliminary experiments have shown that storage at room temperature of cultures of strains lacking pAV2 revealed a certain degree of phenotypic instability and $\mathrm{Mdd}^{\mathrm{ng}}$ segregants were readily isolated; some of these gradually reverted over 3 to 4 months but C4223 has remained stable (Table 4).

Mutant C4226 (mdd-2). Several putative mutants blocked in the mandelate pathway were difficult to isolate as pure strains because on repeated subculturing they showed continuous sectoring of $\mathrm{Mdd}^{\circ}$ and $\mathrm{Mdd}^{\text {no }}$ zones within the colonies. Mutant C4226 was successfully isolated from the auxotrophic strain C48, but it did give Mdd' revertants at low frequency (Table 4) and these showed consistent changes in the plasmid profile of the strains, involving an increase in size of about $7 \mathrm{MDal}$ in a large cryptic plasmid as well as the appearance of a novel plasmid band of about $14 \mathrm{MDal}$ (D. Vakeria \& A. Vivian, unpublished observations). Strain C4226 did not grow on $D(-)$-mandelate (Table 2), presumably because of failure to induce sufficient $D(-)$ mandelate dehydrogenase activity in the presence of $D(-)$-mandelate (Table 3 ). It had about half the $D(-)$-mandelate dehydrogenase activity of the wild-type strain when grown in the presence 


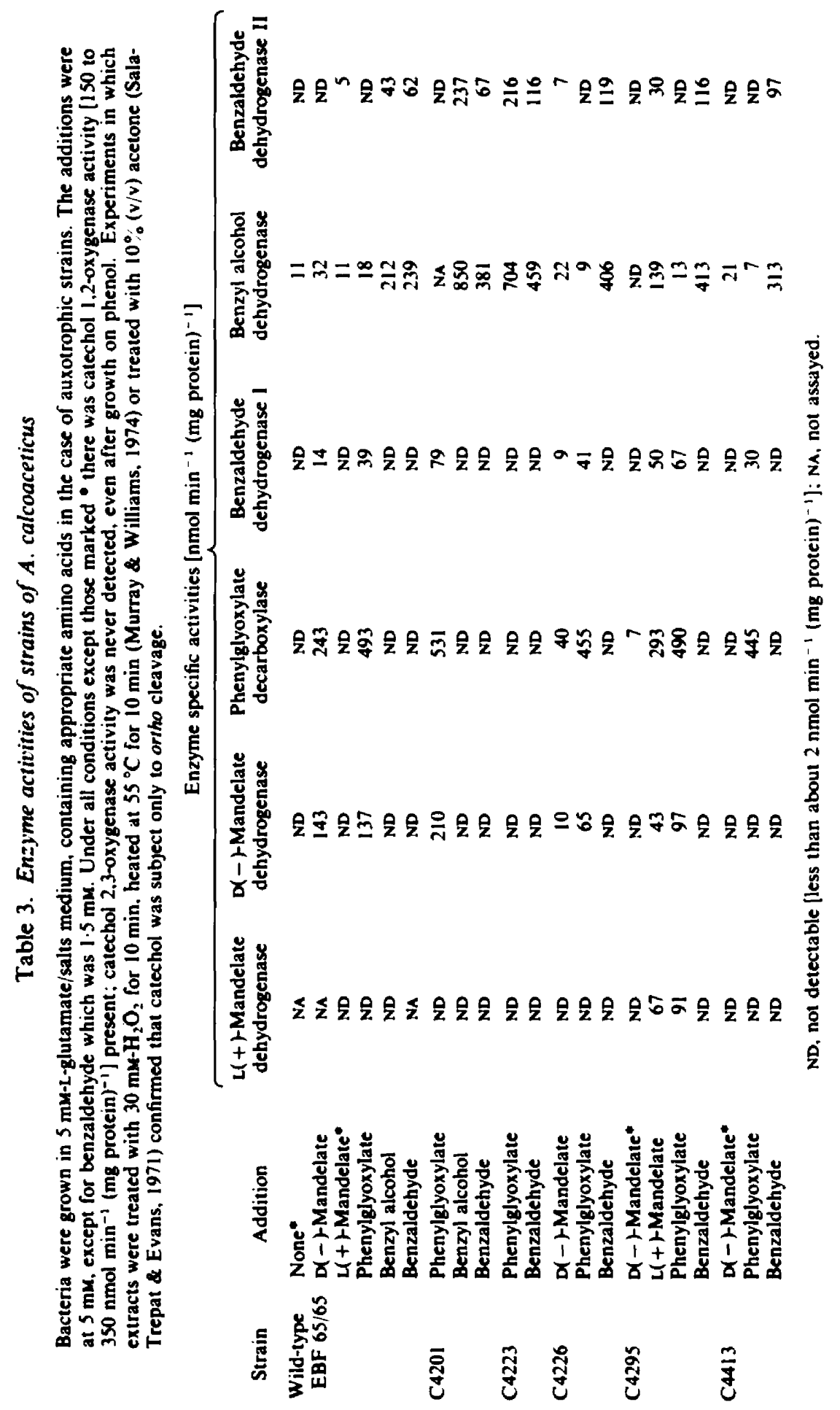


Table 4. Reversion of auxotrophic and catabolic markers

Reversion of auxotrophic markers was tested on minimal medium and reversion of catabolic markers on salts medium containing appropriate supplements.

$\begin{array}{crrr}\begin{array}{c}\text { Auxotrophic } \\ \text { marker }\end{array} & \begin{array}{c}\text { Frequency of } \\ \text { reversion }\end{array} & \begin{array}{c}\text { Catabolic } \\ \text { marker }\end{array} & \begin{array}{c}\text { Frequency of } \\ \text { reversion }\end{array} \\ \text { cyss-3 } & 3.0 \times 10^{-10} & \text { mdd-l } & 2.4 \times 10^{-9} \\ \text { ile-l } & 5.5 \times 10^{-9} & \text { mdd-2 } & 1.5 \times 10^{-8} \\ \text { met-l } & <5.5 \times 10^{-4} & \text { mdd-3 } & <3.8 \times 10^{-10} \\ \text { phe-l } & 1.8 \times 10^{-8} & p g c-l & 4.8 \times 10^{-9} \\ \text { thi. } & 1.8 \times 10^{-8} & & \end{array}$

of phenylglyoxylate (Table 3 ); it is possible that the mutation altered the uptake of $D(-)$ mandelate into the bacteria or in some way interfered with the operation of $\mathrm{D}(-)$-mandelate dehydrogenase in vito.

Mutant C4295 ( $m d d-2$ mdl-2). Strains possessing a novel L(+)-mandelate dehydrogenase were isolated from a range of parental strains, including mutants in the mandelate pathway, at a frequency of about 2 to $4 \times 10^{-10}$ (Vakeria, 1982). Mutant C4295 (Tables 2 and 3) was isolated as a spontaneous $\mathrm{Mdl}^{9}$ variant from the recombinant strain $\mathrm{C} 4289$ in order to construct a Mdd $^{n 9} \mathrm{Mdl}^{\circ}$ strain suitable for examining possible linkage between the genes for the two mandelate dehydrogenases (although of course mdl mutations are not necessarily in the structural gene for $\mathrm{L}(+)$-mandelate dehydrogenase). Mutant C4295, like C4226, could not grow on $D(-)$-mandelate (Table 2) although some $D(-)$-mandelate dehydrogenase activity was induced during growth in the presence of $L(+)$-mandelate or phenylglyoxylate (Table 3 ).

\section{Mapping of catabolic markers}

Mapping data were analysed in terms of absolute recombinant frequencies and of coinheritance frequencies. Recombination frequencies were in the range $10^{-7}$ to $10^{-2}$, well in excess of the frequencies of reversion (Table 4). Catabolic markers were tested as unselected donor markers (Table 5).

Overall, the map positions of auxotrophic markers agreed with those reported by Towner (1978) on the basis of his experiments with RP4. The chief differences were that ala- $l$ and cys-3 appeared to be in the opposite orientation to that found by Towner (1978) and ile-1, met-1, ala-1, leu-2 and cys-3 appeared to act as a linkage group, perhaps reflecting a feature of mobilization by pAV1 (Vakeria, 1982).

Examination of recombinants from some crosses showed that there was a considerable proportion lacking pAV1. This situation is analogous to that found for RP4 in A. calcoaceticus (Towner \& Vivian, 1976b) and for R68.45 in Rhizobium meliloti (Kondorosi et al., 1977) and $P$. aeruginosa (Haas \& Holloway, 1978).

Mutant C4223 was used in the initial crosses and some of the recombinants obtained were used in subsequent mapping. Since in some recombinants, there was segregation of the ability to utilize $D(-)$-mandelate and phenylglyoxylate, two mutant alleles were designated in $C 4223$ : $m d d-I$ and $p g c-l$. This mutant also lacked benzaldehyde dehydrogenase I activity (Table 3 ) but benzaldehyde was not included amongst the test substrates because poor and irreproducible growth on this rather inhibitory substrate made it difficult to characterize recombinants accurately. Mutant C4413 was also used in the early crosses in order to generate mdd-3 recombinants containing auxotrophic markers. Three donor strains harbouring pAVI were isolated in this way (C4435, C4437 and C4438) and these were in turn used in further crosses to determine co-inheritance of $m d d-3$ with the various auxotrophic markers.

The position of $m d l-l$ had been located by Towner (1978) between phe-l and $t r p-2$ using RP4. This location was confirmed in the present work from crosses involving pAVI. When phe-l was used as the selected donor marker, $p g c-l$ showed $100 \%$ co-inheritance whereas mdd-l, mdd-3, $m d l-l$ and $m d l-2$ showed 70 to $79 \%$ co-inheritance. In at least two different crosses (DV57 and 
Table 5. Co-inheritance frequencies in crosses involving various mutant strains of A. calcoaceticus

Recombinants were selected on appropriately supplemented minimal medium. Unselected catabolic markers were tested on appropriate salts medium.

\begin{tabular}{|c|c|c|c|c|}
\hline $\begin{array}{l}\text { Selected } \\
\text { donor } \\
\text { marker }\end{array}$ & \multicolumn{2}{|c|}{$\begin{array}{l}\text { Co-inheritance }(\%) \\
\text { of unselected donor } \\
\text { marker with selected } \\
\text { donor marker }\end{array}$} & \multirow{2}{*}{$\begin{array}{c}\begin{array}{c}\text { No. of } \\
\text { colonies } \\
\text { tested }\end{array} \\
194 \\
101 \\
935\end{array}$} & \multirow{2}{*}{$\begin{array}{l}\text { Designation of cross } \\
\text { DV55 and DV57: both C4408 } \times \text { C4183 } \\
\text { DV45: C4279 } \times \text { C4290 } \\
\text { DV15 and DV22: both C4151 } \times \text { C4223. } \\
\text { C4185 } \times \text { C4223. DV45: C4279 } \times \text { C429 }\end{array}$} \\
\hline $\begin{array}{l}\text { cys-3+ } \\
\text { met-1+ } \\
\text { phe- } I^{+}\end{array}$ & $\begin{array}{l}\text { mdd-1 } \\
27(21-33) \\
27(20-33) \\
79(64-94)\end{array}$ & $\begin{array}{l}p g c-I \\
47(32-63) \\
30(27-33) \\
\quad 100\end{array}$ & & \\
\hline $\begin{array}{l}\text { ile-1" } \\
\text { met-1+ } \\
\text { phe-1+ }\end{array}$ & \multicolumn{2}{|c|}{$\begin{array}{l}67(58-75) \\
68(64-71) \\
79(69-91)\end{array}$} & $\begin{array}{l}111 \\
106 \\
325\end{array}$ & $\begin{array}{l}\text { DV242: C4438 } \times \text { C4664 } \\
\text { DV242: C4438 } \times \text { C4664 } \\
\text { DV224: C4435 } \times \text { C484. DV225: C4437 } \times \text { C484. DV226: }\end{array}$ \\
\hline 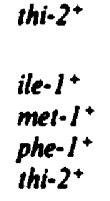 & \multicolumn{2}{|c|}{$\begin{array}{c}76(75-77) \\
76(66-90) \\
66(65-67) \\
0\end{array}$} & $\begin{array}{r}159 \\
154 \\
41 \\
111\end{array}$ & $\begin{array}{l}\text { DV228: C4440 ×C4664. DV242: C4438 } \times \text { C4664 } \\
\text { as for ile- } l^{+} \text {selection } \\
\text { DV227: C4441 } \times C 484 \\
\text { DV227: C4441 } \times C 484\end{array}$ \\
\hline $\begin{array}{l}\text { ile- } 1^{+} \\
\text {met-1+ } \\
\text { phe-1+ } \\
\text { thi-2 }\end{array}$ & \multicolumn{2}{|c|}{$\begin{array}{c}37 \\
38(33-43) \\
70(67-72) \\
4(3-4)\end{array}$} & $\begin{array}{l}49 \\
99 \\
84 \\
94\end{array}$ & $\begin{array}{l}\text { DV237: C4440 } \times C 4248 \\
\text { DV237:C4440 } \times C 4248 \\
\text { DV229: C4439 } \times C 484 \\
\text { DV229: C4439 } \times C 484\end{array}$ \\
\hline $\begin{array}{l}\text { cys-3* } \\
\text { phe-1+ }\end{array}$ & \multicolumn{2}{|c|}{$\begin{array}{l}m d l-2 \\
36(31-45) \\
77(64-92)\end{array}$} & $\begin{array}{l}194 \\
420\end{array}$ & $\begin{array}{l}\text { DV55 and DV57: both C } 4408 \times C 4183 \\
\text { DV55 and DV57 as above. DV58: C } 4408 \times C 4290\end{array}$ \\
\hline ile-1+ & \multicolumn{2}{|c|}{$\begin{array}{l}\text { met-l } \\
94(86-100)\end{array}$} & 1492 & 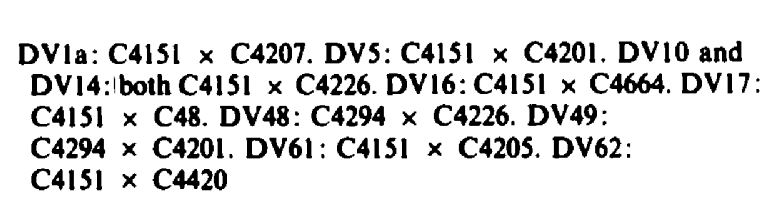 \\
\hline$m e t-1^{+}$ & \multicolumn{2}{|c|}{$\begin{array}{l}\text { ile-l } \\
(95-100)\end{array}$} & 1091 & $\begin{array}{l}\text { DVla, DV5, DV10, DV14, DV16, DV48, DV49, DV61, } \\
\text { DV62 as above }\end{array}$ \\
\hline met-1+ & \multicolumn{2}{|c|}{$\begin{array}{l}\text { cys-3 } \\
87(77-96)\end{array}$} & 108 & DV44: C4279 × C4289. DV45: C4279 × C4290 \\
\hline met-1+ & \multicolumn{2}{|c|}{$\begin{array}{l}\text { phe-l } \\
29(24-35)\end{array}$} & 153 & DV 44 and DV 45 as above \\
\hline phe-1 ${ }^{+}$ & \multicolumn{2}{|c|}{ met-l } & 112 & DV38: C4267 x C4103. DV44 as above \\
\hline phe-1+ & \multicolumn{2}{|c|}{$\begin{array}{l}\text { thi-2 } \\
50(44-55)\end{array}$} & 364 & DV22: C4151 × C4223. DV31: C4185 × C4223 \\
\hline
\end{tabular}

- Values in parentheses indicate the range of co-inheritance frequencies obtained from different crosses and counterselections.

DV58), a strain carrying $m d d-l$ and $p g c-l$ alleles was mated with a strain carrying $m d l-2$. Out of 420 colonies tested from the phe-1+ $1^{+}$selection, $100 \%$ were $\mathrm{Pgc} ; 79 \%$ were Mdd and $94 \%$ of these Mddo colonies were also Mdl9. Similarly, on cys $-3^{+}$selection, 194 colonies were tested, of which about $27 \%$ were $\mathrm{Mdd}$, and $92 \%$ of these Mdd colonies were also Mdlo. It is not known why there was segregation between the mdd-l and pgc-l alleles when $\mathrm{C4223}$ (lacking regulon-1 enzymes) was used in crosses. The results indicate that not only are pgc- $I$ and $m d d-I$ probably 
Table 6. Analysis of the recombinants from a cross (DV242) involving strain C4438 (ala-l his-I trp-2 mdd-3, pAVI) and strain C4664 (ile-l met-1 mdc-1)

\begin{tabular}{|c|c|c|c|}
\hline Selection & $\begin{array}{l}\text { No. of } \\
\text { colonies } \\
\text { tested }\end{array}$ & $\begin{array}{l}\text { No. of } \\
\text { inducible } \\
\text { colonies }\end{array}$ & $\begin{array}{l}\text { No. of colonies } \\
\text { that were inducible } \\
\text { and failed to grow } \\
\text { on } D(-) \text {-mandelate }\end{array}$ \\
\hline 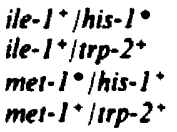 & $\begin{array}{l}56 \\
55 \\
51 \\
55\end{array}$ & $\begin{array}{l}42 \\
41 \\
36 \\
36\end{array}$ & $\begin{array}{l}42 \\
32 \\
36 \\
35\end{array}$ \\
\hline Total & 217 & 155 & 145 \\
\hline
\end{tabular}

linked but the $m d l-2$ and $m d d-l$ loci are probably also close together. This was the first indication of linkage between genes involved in the activities of $\mathrm{D}(-)$-mandelate dehydrogenase and $\mathrm{L}(+)$ mandelate dehydrogenase and is consistent with the co-ordinate physiological regulation of the two enzymes (Hills \& Fewson, 1983b). The loci $m d l-1$ and $m d l-2$ may well be in the same gene.

Although the mdd-2 mutation was used in eight different crosses its location was not clear since it failed to map consistently in one position.

Results from other crosses involving $m d d-3$ and $m d c-1$ alleles indicated that they did not appear to be located very close to $m d d-1, p g c-l, m d l-l$ and $m d l-2 ;$ mdc-l showed a slightly higher percentage co-inheritance with ile-l and met- 1 than with phe-l. Similarly, although $m d d-3$ showed $79 \%$ co-inheritance with phe- $I$, it showed much higher co-inheritance with ile- $I$ and met$l(67 \%)$ than did mdd-1, pgc-l, mdl-l or mdl-2. The markers met-l, ile-l and cys-3 appear to be closely linked (Table 5). It is possible that $m d c-l$ and $m d d-3$ are located between met $-I$ and phe- $I$ with $m d c-l$ closer to met- $I$ and $m d d-3$ closer to phe- $I$. A cross was made in which the donor strain carried the $m d d-3$ mutation and was inducible $\left(m d c^{+}\right)$for the regulon-1 enzymes. The recipient strain was mandelate-proficient $\left(m d d-3^{+}\right)$but carried the $m d c-I$ allele. Out of 217 recombinants analysed, 155 were found to be inducible and $94 \%$ of these inducible colonies had concomitantly gained the Mddng phenotype (Table 6). This suggested possible linkage between $m d d-3$ and $m d c-I$ and it follows that the mutations $m d d-I$ and $m d d-3$ are probably located in different genes. This is further suggested by the isolation of Mddo recombinants at a frequency of $5 \times 10^{-7}$ from a cross involving the $m d d-3$ and $m d d-1 / p g c-I$ alleles; these colonies could not simply represent revertants because the reversion frequencies were low (Table 4).

\section{Conclusions}

The results from the mapping experiments described in the present paper suggest that, as with $P$. putida (Wheelis \& Stanier, 1970; Wheelis, 1975) and P. aeruginosa (Rosenberg \& Hegeman, 1969), several of the genes concerned with mandelate metabolism in $A$. calcoaceticus EBF $65 / 65$ are chromosomal. Strain EBF 65/65 contains at least seven plasmids (Hinchliffe et al., 1980; A. Vivian and D. Vakeria, unpublished results); however, 'curing' agents such as acriflavine, novobiocin or ethidium bromide failed to affect mandelate metabolism (Vakeria, 1982). Attempts to cure putative plasmids for mandelate or benzyl alcohol degradation in wild-type strain NCIB 8250 (which contains at least two plasmids; Vakeria, 1982) also failed (Fewson, 1978). Similarly, Keil et al. (1983) concluded that it was unlikely that there was a correlation between the ability of various strains of Acinetobacter to degrade certain aromatic carboxylic acids and the presence of plasmid DNA.

The mutants we have isolated are useful for physiological and biochemical studies but our mapping work has been hampered by a shortage of suitable mutants blocked in the catabolic pathways. Mapping studies with $\boldsymbol{P}$. putida and $\boldsymbol{P}$. aeruginosa also appear to have used rather few mandelate markers. We have experienced considerable difficulties in isolating appropriate mutants blocked in either the mandelate or the benzyl alcohol pathways from wild-type strains EBF $65 / 65$ or NCIB 8250 but have had no problems in isolating auxotrophic mutants; it is not clear whether the difficulty has arisen as a result of failure to design suitable enrichment 
techniques or as a consequence of some inherent property of the genetic regulation of the pathways. The present experiments have strengthened the impression gained from previous work that there is some sort of interaction between regulons 1 and 2 .

The positions of the mandelate markers we have mapped so far in $A$. calcoaceticus indicate that there is unlikely to be a single operon; for instance phe-I intervenes between mdc-1, mdd-3 and $p g c-1, m d d-1, m d l-1, m d l-2$. Nevertheless there is a considerable degree of gene clustering, as with the mandelate pathway of $P$. aeruginosa (Rosenberg \& Hegeman, 1969). The apparent linkage between $m d d-1$ and $m d l-l, m d l-2$ strengthens the notion that the 'novel' mandelate dehydrogenases in $A$. calcoaceticus (in this case $\mathrm{L}(+)$-mandelate dehydrogenase) arise as a result of expression of silent genes closely related to those coding for the 'original' mandelate dehydrogenases (Hills \& Fewson, 1983a, b).

This work was supported by grants from the Medical Research Council and the authors are also grateful for the technical assistance of Mr A. Scott.

\section{REFERENCES}

Ahlquist, E. F., Fewson, C. A. \& Ritchie, D. A. (1975). The induction of mutants of Acinetobacter calcoaceticus NCIB 8250 and their selection by vancomycin. Journal of General Microbiology 91 . 338-344.

BARTh, P. T. \& GRINTER, N. J. (1977). Map of RP4 derived by insertion of transposon C. Journal of Molecular Biology 113, 455-474.

Begos, J. D. \& Fewson, C. A. (1977). Regulation of synthesis of benzyl alcohol dehydrogenase in Acinelobacter calcoaceticus NCIB 8250. Journal of General Microbiology 103, 127-140.

Bhat, S. G. \& Vaidyanathun, C. S. (1976). Involvement of 4hydroxymandelic acid in the degradation of mandelic acid by Pseudomonas concexa. Journal of Bacteriology 127, 1108-1118.

Chakrabarty, A. M. \& Gunsalus, I. C. (1969). Defective phage and chromosome mobilization in Pseudomonas putida. Proceedings of the National Academy of Sciences of the United States of America 64. $1217-1223$

Chakrabarty, A. M., Gunsalus, C. F. \& Gunsalus, 1. C. (1968). Transduction and the clustering of genes in fluorescent pseudomonads. Proceedings of the National Academy of Sciences of the United States of America 60. 168-175.

Demerec, M., Adelaerg, E. A., Clark, A. J. \& Hartman, P. E. (1966). A proposal for a uniform nomenclature in bacterial genetics. Genetics 54,61 76.

Errington, J. (1981). The genetics of Pseudomonas morsprunorum. PhD thesis, Council for National Academic Awards, Thames Polytechnic, London.

Fewson, C. A. (1978). Repression of benzyl alcohol dehydrogenase after growth of Acinetobacter calcoaceticus on phenylglyoxylate is not caused by loss of a plasmid. Proceedings of the Society for General Microbiology 5, 109.

Fewson, C. A., Livingstone, A. \& Moyes. H. M. (1978). Mutants of Acinetobacter calcoaceticus NCIB 8250 constitutive for the mandelate enzymes. Journal of General Microbiology 106. 233-239.

HaAs, D. Holloway, B. W. (1978). Chromosome mobilization by the $R$ plasmid R68.45: a tool in Pseudomonas genetics. Molecular and General Genetics 158, 229-237.
Hegeman, G. D. (1966). Synthesis of the enzymes of the mandelate pathway by Pseudomonas putida. 1 . Synthesis of enzymes by the wild type. Journal of Bacteriology 91. 1140-1154.

Hegeman, G. D. \& Root, R. T. (1976). The effect of a non-metabolizable analog on mandelate catabolism in Pseudomonas putida. Archites of Microbiology 110 , 19-25.

Hills, C. A. \& Fewson, C. A. (1983a). Mutant strains of Acinetobacter calcoaceticus possessing additional mandelate dehydrogenases. Identification and preliminary characterization of the enzymes. Biochemical Journal 209. 379.-386.

Hills, C. A. \& Fewson, C. A. (1983b). Regulation of expression of novel mandelate dehydrogenases in mutants of Acinetobacter calcoaceticus. Journal of General Microbiology 129, 2009-2015.

HiNCHLIFFE, E. ViviAN, A. (1980a). Naturally occurring plasmids in Acinetobacter calcoacericus: a P class $\mathbf{R}$ factor of restricted host range. Journal of General Microbiology 116, 75-80.

Hinchliffe, E. \& ViviaN, A. (1980b). Gene transfer in Acinetobacter calcoaceticus: fertility variants of the sex factor pAVI. Journal of General Mirrohiology 119. $117-122$.

Hinchliffe. E., Nugent, M. E. Vivian, A. (1980). Naturally occurring plasmids in Acinetobacter calcoaceficus: pAV2, a plasmid which influences the fertility of the sex factor pAVI. Journal of General Microbiology 121, $411-418$.

KeIL, H., Trtmann, U. \& Lingens, F. (1983). Degradation of aromatic carboxylic acids by Acinetobacter. Systematic and Applied Microbiology 4 , 313-325.

Kemp, M. B. \& Hegeman, G. D. (1968). Genetic control of the $\beta$-ketoadipate pathway in Pseudomonas aeruginosa. Journal of Bacteriology 9.1488 1499.

Kenyon, G. L. \& Hegeman, G. D. (1979). Mandelate racemase. Advances in Enzymology and Related Areas of Molecular Biology 50, 325-360.

Kondorosi, A., Kiss, G. B., Forral, T., Vincze, E. \& Banfalvi. Z. (1977). Circular linkage map of Rhizobium meliloti chromosome. Nature, London 268, 525-527.

LEIDIOH, B. J. \& WhEELIS, M. L. (1973). The clustering 
on the Pseudomonas putida chromosome of genes specifying dissimilatory functions. Journal of Molecular Evolution 2, 235-242.

Livingstone, A. Fewson, C. A. (1972). Regulation of the enzymes converting L-mandelate into benzoate in bacterium NCIB 8250. Biochemical Journal 130. $937-946$.

Livinostone, A., Fewson, C. A., Kennedy, S. I. T. \& ZATMaN, L. J. (1972). Two benzaldehyde dehydrogenases in bacterium NCIB 8250 . Distinguishing properties and regulation. Biochemical Journal 130 , 927-935.

MURRaY, K. \& Willinus, P. A. (1974). Role of catechol and the methylcatechols as inducers. of aromatic metabolism in Pseudomonas putida. Journal of Bacteriology 117, 1153-1157.

Novick, R. P., Clowes, R. C., Cohen, S. N., Curtiss, R., DAtTA, N. \& FAlkow, S. (1976). Uniform nomenclature for bacterial plasmids: a proposal. Bacteriological Reviews 40, 168-189.

rosenberc, S. L. \& Hegeman, G. D. (1969). Clustering of functionally related genes in Pseudomonas aeruginosa. Journal of Bacteriology 99, 353-355.
Sala-Trepat, J. M. E Evans, W. C. (1971). The meta cleavage of catechol by Azotobacter species. 4Oxalocrotonate pathway. European Journal of Biochemistry 20, 400-413.

TOWNER, K. J. (1978). Chromosome mapping in Acinetobacter calcoaceticus. Journal of General Microbiology 104, 175-180.

TOWNER, K. J. \& VIVIAN, A. (1976a). RP4-mediated conjugation in Acinetobacter calcoaceticus. Journal of General Microbiology 93, 355-360.

TOWNER, K. J. \& VIVIAN, A. (1976b). RP4 fertility variants in Acinetobacter calcoaceticus. Genetical Research 28, 301-306.

VAKERLA. D. (1982). Genetic aspects of mandelate catabolism in Acinetobacter calcoaceticus. PhD thesis, Council for National Academic Awards, Thames Polytechnic, London.

WheELIs, M. L. (1975). The genetics of dissimilarity pathways in Pseudomonas. Annual Review of Microbiology 29, 505-524.

Wheelis, M. L. \& Stanier, R. Y. (1970). The genetic control of dissimilatory pathways in Pseudomonas purida. Generics 66, 245-266. 